\title{
Experimental Investigations on the Ignition Delay Time of Freely Falling Liquid Fuel Droplets
}

\author{
Narayan P. Sapkal \\ Department of Mechanical Design Engineering, Pukyong National University, Daeyeon Campus: (48513) 45, Yongso-ro, \\ Nam-Gu, Busan, South Korea
}

Corresponding Author Email: narayanpsapk@pukyong.ac.kr

https://doi.org/10.18280/ijht.390336

Received: 5 June 2020

Accepted: 3 June 2021

\section{Keywords:}

ignition delay time, free falling droplets, hydrocarbons, viscosity, volatility, negative temperature coefficient

\begin{abstract}
The ignition delays of freely falling liquid fuel droplets in a high-temperature environment were determined experimentally as a function of the surrounding parameters and droplet composition. Two different groups of fuels have been categorized based on the viscosity and volatility of each fuel. In the first group, for diesel and kerosene, the ignition delay time decreases with increasing system temperature due to low viscosity and thereby high volatile nature of fuels. Whereas, in the second group, C-heavy oil and blended renewable fuel shows an increase in the ignition delay time with increasing the system temperature and thereby shows the negative temperature coefficient (NTC) behavior due to high viscosity and low volatile characteristics of those fuels. In the case of low viscosity carbon residue fuels with low ignition temperature, they may vaporize early and decrease in the ignition delay time. But for high viscosity carbon residue fuels and with high ignition temperature, it may prolong the vaporization time and thereby physical delay. Evidently, the physical parameters and therefore the physical delay are the predominant factors in the NTC behavior of such high hydrocarbon liquid fuel droplets.
\end{abstract}

\section{INTRODUCTION}

It is important to know the combustion of single fuel droplet in gas turbines and diesel engines. Since the ignition delay and burning velocity of fuel have a major influence on the design and performance of those devices. Spalding [1, 2] Godsave [3, 4] and Kumagai and Isoda [5] study about the combustion of single fuel droplet and expand their study to theoretical work. It is mention that, when a single fuel drop suddenly injected into a high temperature surrounding, the droplet get heat to increase the temperature and the gasification occurs. When equivalent ratio and temperature of fuel air mixture reach to their threshold value, the combustion reaction becomes fast and then auto-ignition occur. This overall time duration between drop injection and auto-ignition is termed as the ignition delay time. Also, some experiments were conducted by Faeth and Olson [6] and Bernard and Willis [7] to study ignition delay time. Their experimental data notify that, the surrounding temperature has an important role on droplet ignition delay time. Furthermore, experiments were performed by Tsue et al. [8] on auto-ignition of single fuel droplet in lean fuel-air mixtures and inspected the effect of fuel gas existence on the droplet ignition behavior.

The ignition phenomena of fuel droplet includes three basic processes are droplet heating, vaporization and chemical kinetics. Due to the rapid growth in computer technology and simulation it is possible to obtain the reaction mechanism for combustion and auto-ignition of single fuel droplet. The effects of various parameters such as, initial conditions, surrounding temperature and drop diameter studied on the ignition delay time by Stauch et al. [9, 10]. In addition, he explored the auto-ignition of n-heptane and iso-octane drops.
For surrounding temperature lower than $1000 \mathrm{~K}$, the ignition delay time increases with an enhancing volume fraction of the iso-octane and it was independent on the mixture composition for temperature higher than $1000 \mathrm{~K}$. Recent developments in the modeling of fuel droplet heating and evaporation reviewed by Sergei [11]. They have explored in detail about the drop heat and evaporation phenomena in detail. Also, Sazhin [12] discusses about recent progress in the development of a combined analytical, asymptotic and numerical approach to modelling of heating and evaporation of fuel droplets and ignition of a fuel vapor/air mixture. They approached to the combined analytical and numerical modelling of droplet heating and evaporation by convection and radiation from the surrounding hot gas. Wang et al. [13] clarified the influence of ambient temperature on $n$-heptane droplet evaporation and established the evaporation model for single droplet in the convection heat environment. Moreover, the analysis of water droplet evaporation was carried out through theoretical and numerical model by Lorenzini and Saro [14]. In addition, injection method in diesel engine [15] and performance of CI engine [16] was observed previously. Also the ignited flame characteristics were studied in the literature [17].

By considering all the background research on fuel droplet ignition we came to know that the ignition delay time is an important fuel characteristic which is the measure of flame ignition capability and continuous ability of flame in the boiler as the characteristic time scale of the combustion. Therefore, it is necessary to construct an experimental device to measure the accurate fuel ignition delay time. In the present study, we try to establish the experimental methodology by calibrating the pump flow rate and drop size generated through microsyringe and dropping the fuel droplet into the high temperature 
system. Four types of fuels were used to check the ignition criteria. Among them diesel and kerosene are well known fuels used in industrial applications. There are very few research and data are available for their ignition characteristics and criteria at high temperature surrounding. In addition, we have considered two more high carbon fuels to check their ignition criteria at high temperature surroundings which might be useful for industrial application. In this way, present study deals with the behavior of ignition delay time of single fuel droplet falling through a high temperature ambience in drop tube furnace (DTF) system.

\section{EXPERIMENTAL FACILITY}

Figure 1(a), shows the schematic diagram of the experimental facility for the study of falling liquid fuel droplets in a high temperature surrounding. The experimental apparatus used in this study consists of drop tube furnace (DTF) system, a syringe pump (Fusion touch 200), microsyringe of $1 \mathrm{ml}$ size, a photodiode sensor and a visualization system. Different types of liquid fuels are used. The DTF heating furnace used in this study is $220 \mathrm{~V}$ single phase and $18 \mathrm{~kW}$ in power. Temperature controller was operated by Proportional Integral Derivative (PID) Control method. In order to make temperature of the furnace up to $1500^{\circ} \mathrm{C}$ around the reactor of size $190 \times 190 \times 650(\mathrm{~W} \times \mathrm{D} \times \mathrm{H}) \mathrm{mm}$, the heat is accumulated in a triple high temperature insulation material. Experiments have been performed in the temperature range of $900^{\circ} \mathrm{C}$ to $1250^{\circ} \mathrm{C}$. Temperature was measured by using B-type thermocouple.

A fuel injection probe of $60 \mathrm{~cm}$ in length and $2.5 \mathrm{~cm}$ in inner diameter was placed inside the DTF at top position as shown in Figure 1(a) and (b). Cooling water was supplied around the injection probe to avoid heating of injection probe. A Syringe pump was used to supply the fuel and droplets were formed by micro-syringe of $1 \mathrm{ml}$ size. A digital video camera (SONY, HDR-SR12) was used to observe the droplet size before free falling into the injection probe during pre-ignition period. The droplet diameter $(d)$ was varied in the range of $2.1 \pm 0.05 \mathrm{~mm}$. Falling drop is of ellipsoidal shape. So the droplet diameter is measured using the following formula [6].

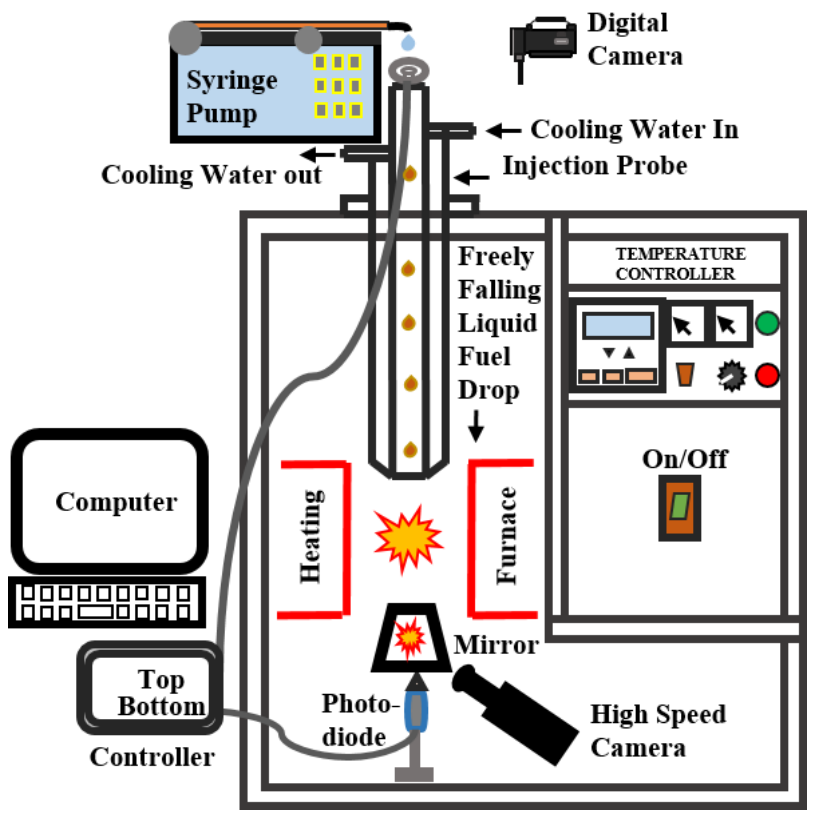

(a)

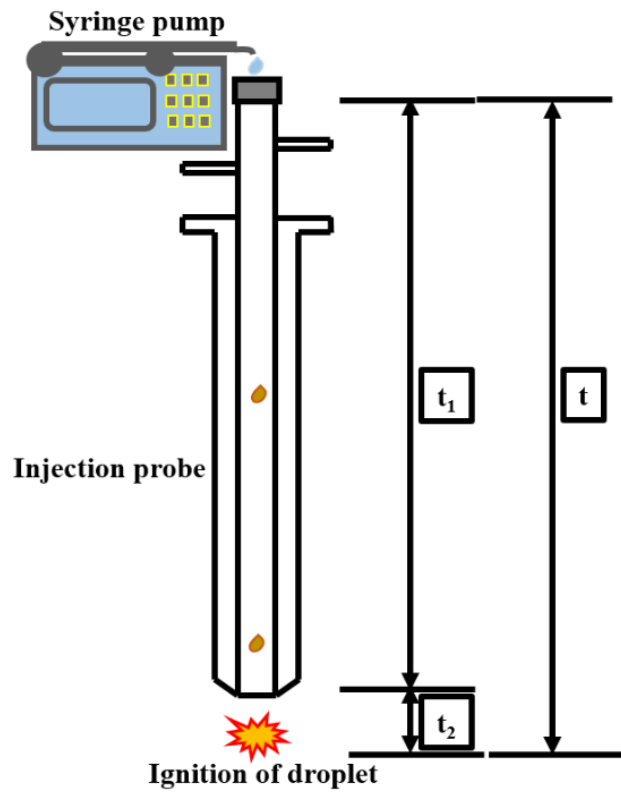

(b)

Figure 1. Schematic diagram of (a) experimental set-up (b) fuel injection probe

$$
D=\left(D_{1}^{2} D_{2}\right)^{\frac{1}{3}}
$$

where, $D_{1}$ is the horizontal diameter and $D_{2}$ is the vertical diameter.

The photodiode flame sensor (HAMAMATSU, UVTRON R2868) of spectral sensitivity of $185 \mathrm{~nm}$ to $260 \mathrm{~nm}$ and response time of $10 \mathrm{~ms}$ was used to detect the droplet ignition event inside the DTF. It is compact UV sensor with high sensitivity and wide directivity, suitable for quick detection of flame from distance. A mirror was placed at exit of the DTF to detect the droplet ignition flame appearance inside the heating furnace. Ignited flame images appeared on the mirror are captured by using i-speed 3 (Olympus) camera. Natural convection effects are neglected in the analysis and are in this way eliminated in the tests. In addition, all the test compositions of the fuels used in this study are also provided here, as shown in Table 1.

Table 1. Fuel composition

\begin{tabular}{ccccc}
\hline Test Items & Diesel & Kerosene & C-Heavy oil & Blended Renewable Fuel \\
\hline Flash point $\left({ }^{\circ} \mathrm{C}\right)$ & Less than 79 & Less than 79 & 164 & 168 \\
Kinematic Viscosity $\left(\mathrm{mm}^{2} / \mathrm{s}\right)$ at $\left(40^{\circ} \mathrm{C}\right)$ & 2.512 & 1.055 & 147.20 & 429.8 \\
Residual carbon fraction $(\mathrm{m} / \mathrm{m}$ weight $\%)$ & 0.01 & 0.01 & 5.43 & 12.29 \\
Test method ASTM code & D5291-10 & D5291-10 & D5291-10 & D5291-10 \\
Density $\left(\mathrm{kg} / \mathrm{m}^{3}\right)$ at $\left(15^{\circ} \mathrm{C}\right)$ & 825.8 & 791.4 & 932.7 & 980.3 \\
\hline
\end{tabular}




\section{PROCEDURE}

Initially heaters in the drop tube furnace were switched on and they brought to the temperature up to $900^{\circ} \mathrm{C}$. Then temperature was continuously increased and fuel drop (formed by syringe pump) under test was allowed to fall down in the furnace and at the same time droplet image was captured by digital camera to measure droplet size. Each single fuel droplet formed by micro syringe was freely falling through the injection probe. Instantly the sensor placed on top of the injection probe gives the time indication of droplet fall into the injection probe. Syringe pump and photodiode sensor are operated simultaneously by using computer program. Flow rate of micro-syringe in the experiment was fixed to 0.3 $\mathrm{ml} / \mathrm{min}$. Freely falling droplet pass through the injection probe and then enters into the high temperature environment heating furnace for ignition. At the moment of droplet ignition, the temperature of furnace was maintained to the set value. When ignition occurred within the length of the heating furnace, the temperature was stabilized at approximately set value. At the event of droplet ignition photodiode sensor placed at the bottom of DTF, gives the indication of total time, $t$ elapsed during the period of droplet fall and ignition. Time period, $t_{1}$ during the free fall in the injection probe was reduced from the total time elapsed during ignition process. Therefore, the time duration from the moment at which droplet exposed to high temperature surrounding to when a visible flame observed is termed as ignition delay time as shown in the Figure 1(b). This is calculated as below,

$$
\begin{aligned}
& t=t_{1}+t_{2} \\
& t_{2}=t-t_{1}
\end{aligned}
$$

\section{RESULTS AND DISCUSSIONS}

\subsection{Observation and Ignition of liquid fuel droplets}

With the increase of surrounding temperature fuel drop evaporation becomes fast and combustion starts with the ignition. In the present study, ignition delay measurements obtained for four fuels diesel, kerosene, C-heavy oil and blended renewable fuel. For all fuels, certain common phenomenon was observed during the period of droplet formation to droplet ignition. When droplet formed by micro syringe is allow to fall down in the injection probe and thereby into the heating furnace through injection probe, then the drop temperature increased and ignition occurred in the wake of the of the droplet. It shows, yellow flame appeared around the droplet as shown in the Figure 2. Moreover, ignition delay time has been evaluated as the time interval between the droplet leaving the syringe needle and entering into the furnace. The ignition delays for different fuels will be discuss later.

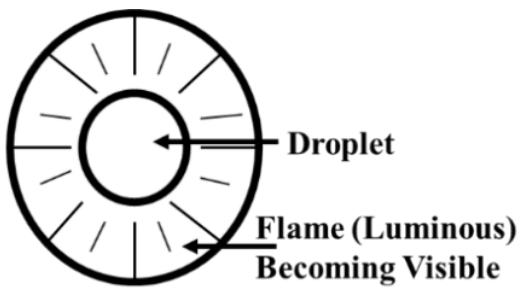

Figure 2. Ignition of fuel droplet falling through DTF

\subsection{Ignition delay time and mechanism}

In the previous sections, the process of droplet formation and ignition have been explained. The visualization of drop ignition inside the DTF, points to the ignition in the wake of the droplet. The photograph taken showed the development of ignition clearly as shown in Figure 3 (a) and (b). To understand the behavior of ignition delay it is necessary to plot temperature-time curves for different fuel drop ignition. Detailed curves of ignition delay time with temperature are shown in Figure 4 (a)-(d), for various liquid fuels and at constant droplet diameter $d=2.1 \mathrm{~mm}$. The results obtained from ignition experiment shows the variation of ignition delay time with temperature for different fuels. There were two groups of fuels for ignition delay time behavior. In the first group, diesel and kerosene liquid fuels have the tendency to decrease in ignition delay time with increase of temperature as shown in Figure 4(a) and (b). Ignition delay time of diesel fuel has a linear relationship with the function of temperature whereas, the kerosene fuel has an exponential behavior as a function of temperature. However, in the second group, Cheavy oil and blended renewable fuels shows the increasing behavior of ignition delay time with increase of temperature as shown in the Figure 4(c) and (d), having linear and exponential relationship respectively as a function of temperature. It means that, second group hydrocarbon fuels show negative temperature coefficient (NTC) behavior. The reason for such NTC behavior will be discussed later. The ignition delay time of a droplet is generally determined for a fixed droplet as follows:

$$
\tau(T, p)=A p^{-n} \exp \left(\frac{E_{a}}{R T}\right)
$$

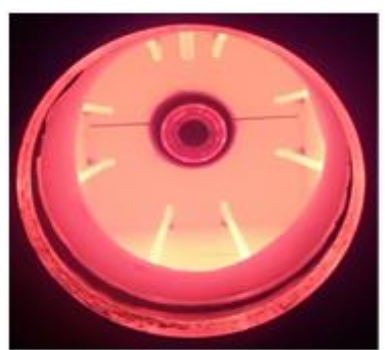

(a)

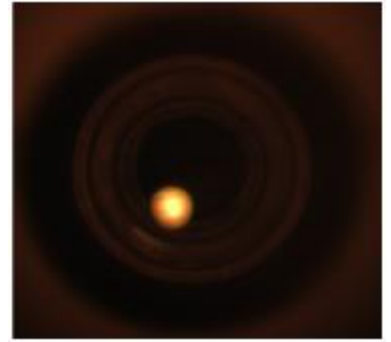

(b)
Figure 3. (a) Inner view of drop tube furnace (DTF) (b) Ignition of droplet inside DTF

Although, the ignition delay time varies depending on the diameter of the droplet, thermal capacity of the fuel and fuel properties etc., it is very difficult to simplify the above general ignition delay characteristics to Arrhenius form in case of negative temperature coefficient (NTC). In addition, when NTC occurs, it is necessary to find the functional expression because there are primary and secondary ignition times. Therefore, it is important to grasp the functional relationship of ignition delay characteristics according to fuel droplet diameter, fuel property and NTC occurrence through experiments of fuels. Hence, it is considered that the evaluation method can be exponentiated by the following method. Since, the fuel droplet diameter $d$, is related to the evaporation rate depending on the heat capacity and diffusivity $D$, differs for each fuel, it can be quantified physically as Damkohler number if the ignition delay time is scaled. On the 
other hand, dependence on the pressure can be eliminated when the pressure is constant, hence the dependence of the primary function can be estimated as,
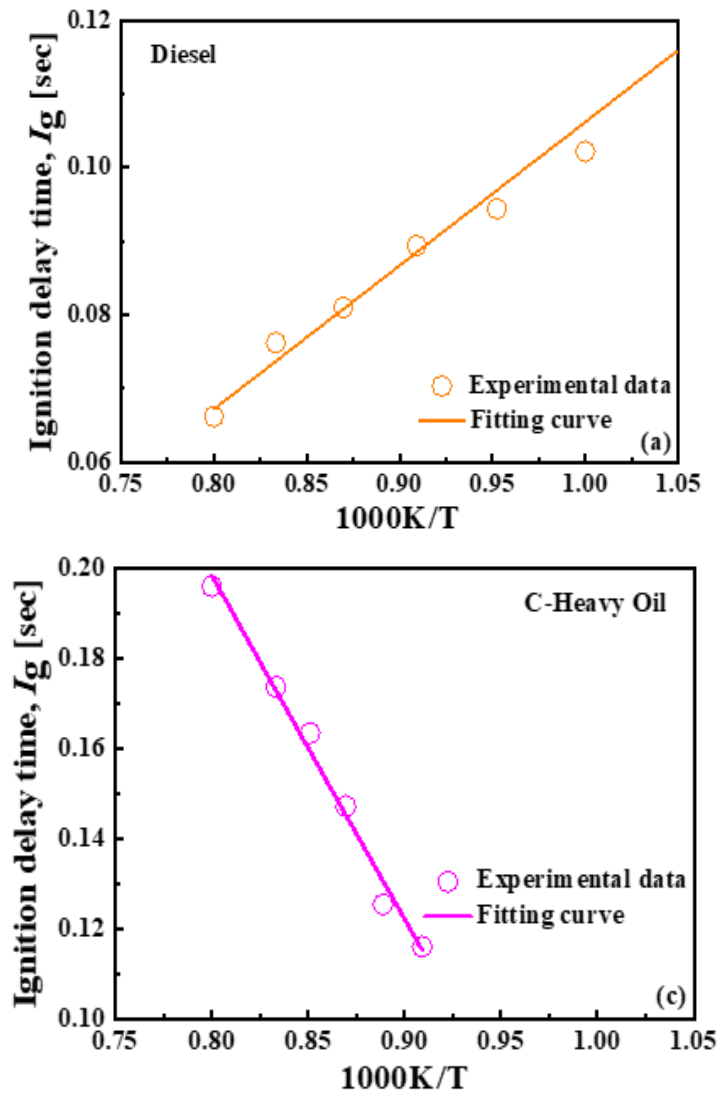

$$
\frac{\tau(T, p)}{\sqrt{\frac{d}{D}}} \sim A \exp \left(\frac{E_{a}}{R T}\right)
$$
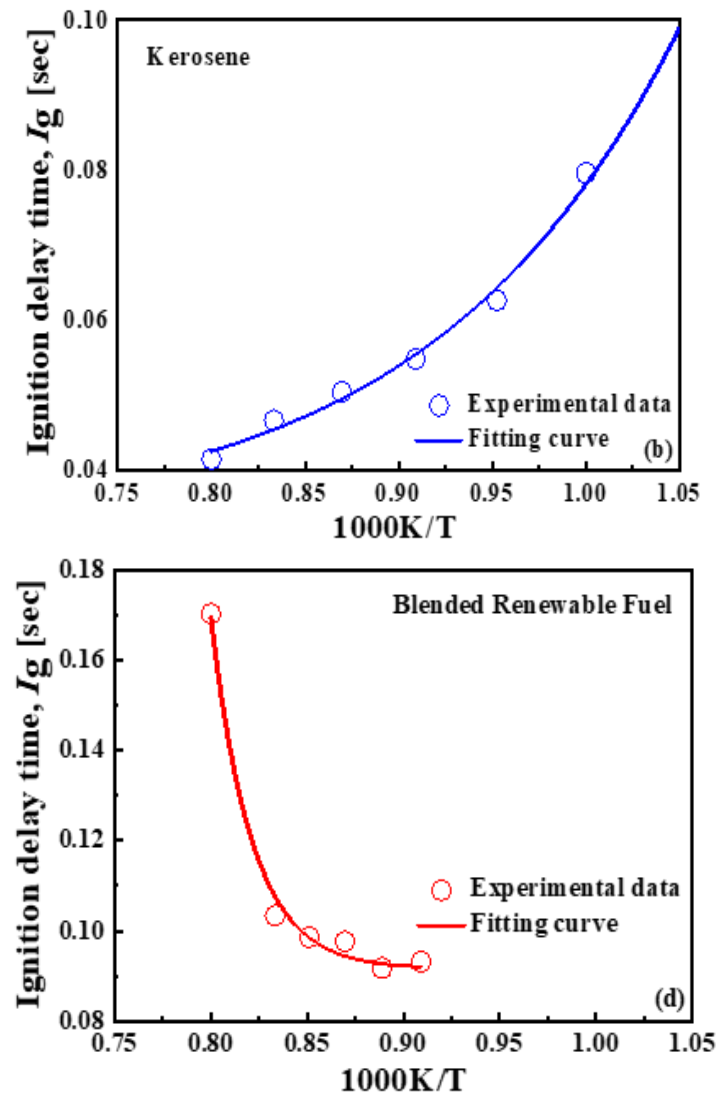

Figure 4. Behavior of ignition delay time $I_{\mathrm{g}}$ with the variation of temperature inside the DTF, for different liquid fuels (a) Diesel (b) Kerosene (c) C-heavy oil (d) Blended renewable fuel

In addition, since the presence or absence of NTC is a characteristics of the fuel, it is necessary to consider a method of estimating the functional relationship by dividing the ignition delay time by the first and second ignition delay times. On the other hand, in the development of the index for each type of fuel, it is possible to use a method of digitizing the fuel index for a single component fuel and developing and quantifying a weighting factor for the mixed fuel. Therefore, the ignition characteristic indexation can be attempted to index with the presence of NTC and the first and second delay time respectively as,

$$
\frac{\tau(T, p)}{\sqrt{\frac{d}{D}}}=f\left(A \exp \left(\frac{E_{a}}{R T}\right)\right)
$$

Now, in the present study the reason of NTC behavior has to be addressed. Based on the, fuel composition in Table 1, diesel and kerosene are the low viscosity and thereby high volatile fuels which ignite by early surface evaporation and hence decrease in the ignition delay with increasing furnace temperature. Whereas, C-heavy oil and blended renewable fuels are the high viscosity and thereby less volatile fuels which may take long time for surface evaporation and thereby ignition delay. In addition, diesel and kerosene are the low carbon residue fuels whereas, the C-heavy oil and blended renewable fuel are the high carbon residue fuels. Here we can compare the experimental results obtained by El-Wakil and Abdou [18]. They mentioned that total ignition delay time increased with increasing number of carbon atoms which is in agreement with the results obtained in this study for high carbon residue fuels as discussed before. Furthermore, high hydrocarbon fuels C-heavy oil and blended renewable fuel may increase the burning phase period and thereby ignition delay time as compared to low carbon fuels diesel and kerosene. Also, the ignition temperature of C-heavy oil and blended renewable fuels are much higher and it prolongs the physical delay compared to the diesel and kerosene as shown in the fuel composition Table 1. By considering all of these parameters, NTC behavior may occur for high hydrocarbon fuels. In this manner, ignition delay time behavior with variation of system temperature is explained for different liquid fuels.

\section{CONCLUSION}

Mechanism of ignition delay is observed experimentally in high temperature environment for freely falling liquid fuel droplets. The behavior of ignition delay time has been categorized into two groups. Ignition delay time decreases with increasing system temperature (for low viscosity and thereby high volatile fuels such as diesel and kerosene) in first group. Whereas, it increases with increasing system temperature (for high viscosity and low volatile fuels such as 
C-heavy oil and blended renewable fuels) and thereby shows negative temperature coefficient (NTC) behavior in the second group. Low viscosity and carbon residue fuels with low ignition temperature may vaporize early and decrease in the ignition delay time. But high viscosity and carbon residue fuels with high ignition temperature may prolong the vaporization time and thereby physical delay. Evidently, the physical parameters and therefore the delay are the influencing factors in the NTC behavior of such high hydrocarbon liquid fuel droplets.

\section{UNCERTAINTY}

Few experimental measurement uncertainties in the present study are shown in the following table:

\begin{tabular}{|c|c|}
\hline Variable & Uncertainty \\
\hline Furnace Inside Temperature & $+/-2 \mathrm{~K}$ \\
\hline Injection Probe Diameter & $+/-1$ millimeter \\
\hline Sensor Response Time & $+/-5$ microsecond \\
\hline Droplet Diameter & $+/-0.05$ millimeter \\
\hline
\end{tabular}

\section{ACKNOWLEDGMENT}

This research was supported by the Korea Institute of Energy Technology Evaluation and Planning (KETEP) of the Republic of Korea.

\section{REFERENCES}

[1] Spalding, D.B. (1950). Combustion of liquid fuels. Nature, 165(4187):

https://doi.org/10.1038/165160a0

[2] Spalding, D.B. (1951). Combustion of fuel particles. Fuel, 30: $121-130$.

[3] Godsave, G.A.E. (1949). Combustion of droplets in a fuel spray. Nature, 164(4173): 708-709. https://doi.org/10.1038/164708b0

[4] Godsave, G.A.E. (1950). Combustion of fuel droplets. Nature, 166(4235): 1111-1111. https://doi.org/10.1038/1661111b0

[5] Kumagai, S., Isoda, H. (1952). Experimental study on evaporation and combustion of fuel droplets. Science of Machine, 4: 337-342.

[6] Faeth, G.M., Olson, D.R. (1968). The ignition of hydrocarbon fuel droplets in air. SAE Technical Paper 680465. https://doi.org/10.4271/680465

[7] Bernard, J.W., Willis, A.R. (1969). An experimental study of fuel droplet ignition. AIAA, 7: 2288-2292. https://doi.org/10.2514/3.5529

[8] Tsue, M., Ishimaru, R., Ukita, T., Nakaya, S., Kono, M. (2006). Spontaneous ignition of fuel droplets in lean fuelair mixture. Journal of Propulsion and Power, 22: 13391347. https://doi.org/10.2514/1.17104

[9] Stauch, R., Lipp S., Maas U. (2006). Detailed numerical simulation of the autoignition of single $n$-heptane droplets in air. Combustion and Flame, 145: 533-542. https://doi.org/10.1016/j.combustflame.2005.12.013

[10] Stauch, R., Mass, U. (2007). The auto-ignition of single n- heptane/iso-octane droplets. International Journal of Heat and Mass Transfer, 50: 3047-3053. https://doi.org/10.1016/j.ijheatmasstransfer.2006.12.005

[11] Sergei S.S. (2017). Modeling of fuel droplet heating and evaporation: Recent results and unsolved problems. Fuel, 196: 69-101. https://doi.org/10.1016/j.fuel.2017.01.048

[12] Sazhin, S. (2005). Modelling of heating, evaporation and ignition of fuel droplets: Combined analytical, asymptotic and numerical analysis. Journal of Physics: Conference $\quad$ Series, 22: 174-193. https://doi.org/10.1088/1742-6596/22/1/012

[13] Wang, J., Wang, X., Ren, W., Xiang, K. (2017). Effect of ambient conditions on n-heptane droplet evaporation, Mathematical Modeling of Engineering Problems, 4(1): 13-17. https://doi.org/10.18280/mmep.040103

[14] Lorenzini, G., Saro, O. (2016). Analysis of water droplet evaporation through a theoretical-numerical model. International Journal of Heat and Technology, 34(2): S189-S198. https://doi.org/10.18280/ijht.34S201

[15] Cantore, G., Mattarelli, E., Rinaldini, C.A., Savioli, T., Scrignoli, F. (2019). Numerical optimization of the injection strategy on a light duty diesel engine operating in dual fuel (CNG/Diesel) mode. International Journal of Heat and Technology, 37(3): 682-688. https://doi.org/10.18280/ijht.370303

[16] Sakhrieh, A.H., Al-Hares, A.N., Faqes, F.A., Al-Baqain, A.S., Alrafie, N.H. (2017). Optimization of oxyhydrogen gas flow rate as a supplementary fuel in compression ignition combustion engines. International Journal of Heat and Technology, 35(1): 116-122. https://doi.org/10.18280/ijht.350116

[17] Sapkal, N.P. (2018). Role of chemiluminescence and radius of curvature in the stabilization of methane/helium lifted flames. International Journal of Heat and Technology, 36(4): 1249-1255. https://doi.org/10.18280/ijht.360412

[18] El-Wakil, M., Abdou, M. (1962). The self ignition of fuel drops in heated air streams. SAE Technical Paper 620284. https://doi.org/10.4271/620284

\section{NOMENCLATURE}

$D$ diffusivity, $\mathrm{m}^{2} \cdot \mathrm{s}^{-1}$

$D_{1} \quad$ short diameter of droplet, $\mathrm{mm}$

$\mathrm{D}_{2} \quad$ long diameter of droplet, $\mathrm{mm}$

$d$ droplet diameter, $\mathrm{mm}$

$E_{\mathrm{a}}$ activation energy, ${\mathrm{J} . \mathrm{mol}^{-1}}^{-1}$

$p$ pressure, $\mathrm{Pa}$

$R \quad$ universal gas constant

$T$ absolute temperature, $\mathrm{K}$

\section{Greek symbols}

$\tau$ dimensionless time

\section{Subscripts}

a pre-exponential factor

$n$ exponent

$f \quad$ fluid (pure water)

$n f$ nanofluid 